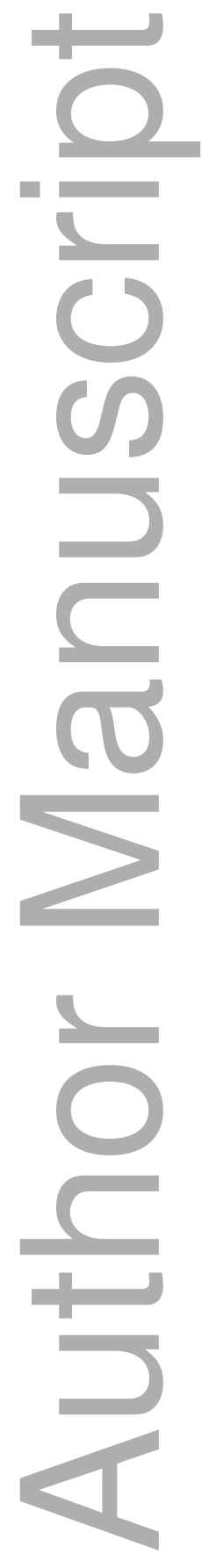

This is the author manuscript accepted for publication and has undergone full peer review but has not been through the copyediting, typesetting, pagination and proofreading process, which may lead to differences between this version and the Version of Record. Please cite this article as doi: $\underline{10.1111 / \text { ecca. } 12259}$

This article is protected by copyright. All rights reserved 


\title{
Should Congestion Tolls be Set by the Government or by the Private Sector? The Knight-Pigou Debate Revisited
}

\author{
By Stephen Salant $\dagger$ and Nathan SeEgert $\ddagger$ \\ - †University of Michigan $\ddagger$ University of Utah \\ Final version received 15 September 2017.
}

This paper clarifies issues debated by A. C. Pigou and Frank Knight about correcting inefficient use of congestible resources, focusing for concreteness on their original example of road congestion. Instead of government-imposed Pigouvian access fees, Knight favoured access fees set by private toll-setters. We consider the case of $n \geq 2$ congestible roads and an uncongestible road of arbitrary speed. Knight argued that in the case of a single congestible road, a private toll-setter would always choose the toll that Pigou recommended, hence the allocation would minimize aggregate commute time without government meddling. We find instead that two or more toll-setters would never choose Pigouvian tolls except in the special case of a sufficiently fast uncongestible road. Moreover, for uncongestible roads of slower speed, the allocation of motorists under Knight's proposal is almost never efficient. Whenever it is inefficient, motorists are strictly worse off when they pay tolls set by private firms instead of paying government-imposed tolls, and aggregate toll revenue is also lower. Nevertheless, if the private sector does set tolls, then the full cost to motorists can be limited if the government provides an uncongestible alternative, such as a train, to offer potential competition along the same route.

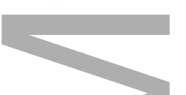

\section{INTRODUCTION}

You could put $\$ 5$ trillion into America's transportation system and if the money isn't directed in the right way, we will still have congestion, still have problems. (Transportation Secretary Anthony Foxx, US News and World Report, 17 January 2017)

You won't build many roads and the ones that you do will have such large tolls that the very middle class people that Donald Trump says he wants to help will be dramatically hurt. (Senate Minority Leader Chuck Schumer, PBS Newshour, 23 January 2017)

According to the American Society of Civil Engineers (ASCE), American drivers spent an average of 42 hours delayed in traffic in 2014. ASCE gave US roads a grade of D in its 2017 infrastructure report card. 'More than two out of every five miles of America's urban interstates are congested and traffic delays cost the country $\$ 160$ billion in wasted time and fuel in 2014' (ASCE 2017). Rectifying this situation is worth many times the cost. According to the Federal Highway Administration, each dollar spent on road, highway and bridge improvements lowers costs to society by $\$ 5.20$.

Despite deep divisions within the US electorate, there is widespread agreement that in order to alleviate traffic congestion, the nation's road infrastructure badly needs repair and expansion. Many on both sides of the political divide agree that motorists should be charged for their use of congestible roads. There is also widespread agreement that motorists will respond to these tolls by using the cheapest route to commute to work, taking into account tolls and lost wages commuting.

The disagreement concerns whether the government or the private sector should be the one to incur infrastructure costs and set road tolls. Liberals argue that the government should borrow to finance these projects, repaying the loans out of toll revenue. ${ }^{1}$ Conservatives, on the other hand, feel that private firms should incur these expenses and then should earn the revenue from tolls of their choosing.

This question is not new. Whether congestion tolls should be set by the government or the private sector was the focus of a famous debate more than 90 years ago between A. C. Pigou and Frank Knight. Pigou (1920) points out that in the absence of government intervention, motorists 
seeking the quickest way to work allocate themselves across roads in a way that fails to minimize aggregate commute time. He uses the example of motorists choosing between two routes to work - a fast, congestible road and a slow, uncongestible alternative. Motorists choose the faster route until congestion slows traffic so much that the uncongestible route is just as attractive; the remaining motorists then use the uncongestible route. Pigou points out, however, that this equilibrium allocation does not minimize aggregate commute time. If a motorist is switched from the congestible road to the uncongestible one, for example, then travel time does not change but the aggregate commute time of those remaining on the congestible road decreases. Pigou shows that to achieve the allocation that minimizes aggregate time lost commuting, the government should charge every motorist using the congestible road a 'Pigouvian' toll, a user fee equal to the aggregate loss in wages imposed on the remaining set of motorists because he added himself to the congestible route.

Knight (1924) counters that government meddling is not required to achieve efficiency; once property rights are properly assigned, such matters can be left to the private sector. He shows that if a profit-maximizing private firm sets the toll on the congestible road, then that firm freely chooses to set a Pigouvian toll, and an efficient allocation results without any need for the government.

It appears that the inefficiency that Pigou had identified was merely an artefact of his formulation, which omitted a private toll-setter on the congestible road. Pigou dropped the congestible road example from subsequent editions of his textbook The Economics of Welfare, an apparent admission of error. ${ }^{2}$

Many have concluded from this debate that private toll-setting can always be relied on to minimize aggregate time wasted commuting. For example, Ellis and Fellner (1943) assert that Pigou's contention 'was proven to be fallacious by Professor Knight'. More recently, Demsetz (2011) reaches a similar conclusion when recounting the two-road example in 'Knight's brilliant article' (Demsetz 2011, p. 3). In Demsetz's retelling, however, the second road becomes slightly congestible and, in addition, acquires a second private toll-setter. Nonetheless, according to Demsetz, 'Knight's private roads and Pigou's recommended tax-subsidy remedy would result in an optimal amount of congestion' (Demsetz 2011, p. 4).

If the lesson that Demsetz and others have drawn from Knight's discussion were correct, then President Trump's plan to delegate toll-setting to the private sector would not needlessly increase the aggregate time workers spend commuting. But, in fact, neither Knight nor anyone since has carefully examined the case of duopoly toll-setting identified by Demsetz. Lacking the gametheoretic tools of modern industrial organization (IO) theory, the literature confined its attention to the case of a single toll-setter.

In this paper, we consider the case of two or more congestible roads - each with its own private toll-setter - and one untolled, uncongestible road of arbitrary speed. We show that for any number of congestible roads, private toll-setters will set a Pigouvian toll, provided that the uncongestible road is fast enough to be part of the solution that minimizes aggregate commute time. We can also reproduce the case considered by Demsetz with two congestible roads and a uncongestible road so slow that its existence is irrelevant. We also consider intermediate cases where the uncongestible road is not fast enough to generate Knight's case or slow enough to generate Demsetz's case.

We show that, as a general matter, Pigou's proposal for government tolls always restores efficiency - for any number of congestible roads and any commute time on the uncongestible road. In contrast, we show that Knight's proposal for private toll-setting is problematic except in the special case where the commute on the uncongestible road is sufficiently fast. If the uncongestible road is slower and there are two or more congestible roads, then private toll-setters never set Pigouvian tolls and almost never achieve the efficient solution. In particular, they never achieve the efficient solution in the case identified by Demsetz where the two roads have different congestion functions and there is no uncongestible alternative. Finally, we show that - except in the special case of a fast uncongestible road-private toll-setting is strictly more costly to each motorist than government-imposed tolls and generates strictly less toll revenue.

Although our findings should make advocates of private-sector toll-setting abandon the idea, we recognize that some policymakers are heavily invested in this solution. Accordingly, we propose a way in which the government can indirectly regulate private toll-setting by providing motorists with an attractive, uncongestible public option for commuting to work. This option would limit the full cost that motorists would incur by using private toll roads. ${ }^{3}$

We have formulated our analysis in terms of roads because that is the congestible resource that Knight, Pigou and Demsetz discussed, and, in addition, because President Trump's plan to improve US roads depends on tolls set by the private sector.

\section{This article is protected by copyright. All rights reserved}


But our analysis applies equally to other congestible resources. If fishermen can choose whether to fish on one of several congestible lakes, for example, then the fishermen will allocate themselves among the lakes in a way that equalizes their earnings on each lake. But this allocation fails to maximize their aggregate earnings because no one takes any account of how they reduce the aggregate fish catch of others fishing on the same lake. Instead of a lake-specific Pigouvian fee imposed by the government to restore efficiency, however, disciples of Knight, such as Demsetz, would recommend empowering one private firm per lake to set a lake-specific access fee in the mistaken belief that the revenue-maximizing fee on each lake would equal the lake-specific Pigouvian tax and would restore efficiency.

Our analysis also applies to other traditional congestible resources such as common oil pools, grazing areas and hunting grounds. These contexts may seem dated and remote, but modern congested resources confront us every day: bridges, tunnels, the internet, the radio frequency spectrum, airport runways (Brueckner 2002; Pels et al. 2000) and the electricity grid (Borenstein et al. 2000).

Congestion problems are ubiquitous, but are not always recognized. To take one example, suppose that there are $N$ biomedical researchers, each of whom can be deployed in the search of a cure for one of $n(n \ll N)$ diseases. Suppose that discovering a cure for each disease has a specified social value. This is a congestion problem since when any researcher seeks a cure for a given disease, he reduces the chance that others searching for a cure for the same disease will be the first to discover one, an effect that a planner would take into account but that a private agent would ignore when deciding which activity to pursue.

A planner could work out how many of the researchers should be deployed on each disease to maximize expected social welfare, and to decentralize this efficient solution, the government could set 'Pigouvian prizes'. However, disciples of Knight would erroneously argue that the government is unnecessary; each of $n$ independent private agents would offer a prize for the first research to find a cure for a given disease in exchange for the right to market the drug. In fact, competing prize-setters will never achieve the efficient allocation of researchers. Moreover, this private-sector solution will always short-change researchers compared to Pigouvian prizes. The government can limit researchers' losses, however, by providing alternative employment research positions (e.g. at the National Institutes of Health) provided that the wage there is high enough to affect the prize-setting equilibrium. ${ }^{4}$

The literature following the Knight-Pigou debate can be divided into two parts, one focused on applications in transportation economics and the other focused on the ability of markets to restore efficiency. ${ }^{5}$ The literature on transportation economics has solved increasingly complex planning problems, often taking into account real-world constraints. For example, William Vickrey promoted congestion tolling for 40 years, expanding the analysis to include land use, parking fees and automated tolls. ${ }^{6}$ A large literature extends this work to second-best pricing cases; for example, when there exist bottlenecks and untolled alternatives (Braid 1989, 1996; Verhoef et al. 1996). ${ }^{7}$ Beckmann et al. (1956) expand the two-road model to an entire transportation network with elastic demand for trips from any point $i$ to any destination $j$. They find that the first-best solution in the expanded model is the same as Pigou's solution with two roads.

The second strand of the literature has examined the validity of Knight's contention that private toll-setting will restore efficiency. Like Knight, contributors to this literature restrict attention to a single private toll-setter. Buchanan (1956) and Edelson (1971) show that Knight's lone toll-setter would not always set Pigouvian tolls but identifies conditions where Knight's contention is correct, such as when motorists have identical wages and access to the same uncongestible alternative. Mills (1981) provides a broader condition for Knight's claim to hold, which encompasses the conditions of Edelson and Buchanan. ${ }^{8}$ Several authors indicate that Knight's contention requires 'competition' from many toll-setters, but, lacking the tools of modern oligopoly theory, they could not be more precise.

Our paper contributes to this second strand of literature. We make assumptions that Buchanan (1956), Edelson (1971) and Mills (1981) show ensure that private toll-setting is efficient when there is a single congestible road. We extend this analysis and ask whether efficiency is ensured when there are two or more congestible roads, each with its own toll-setter, as well as an untolled uncongestible road of arbitrary speed. We also address considerations ignored in the previous literature: whether the welfare of motorists is better and the aggregate toll revenue generated higher under private tolls or government-imposed tolls.

Although Knight, Pigou and their followers assume that one road is uncongestible, many contemporary readers find this assumption implausible. We bridge this divide by assuming that, in 
addition to the $n$ congestible roads, there exists one uncongestible road of arbitrary exogenous speed. If this speed is sufficiently fast, then we get the case discussed by Knight and Pigou; if this speed is sufficiently slow, then we get the case that many contemporary readers (including Demsetz) find more plausible. As we show, the intermediate case is also of interest because it shows the value of a public option in limiting toll-gouging.

As we demonstrate, Knight's result that private toll-setters will set Pigouvian tolls depends on the existence of an uncongestible road of sufficient speed. This is a strong assumption, and the result may disappear if it is altered in seemingly innocuous ways. For example, it may seem that Knight's result would surely continue to hold if the fast uncongestible road were replaced by one that is equally fast and congests only when used by more motorists than a planner would allocate to it. After all, such a substitution would not alter the planning solution. But it would give a monopolist toll-setter an incentive to raise his toll above the Pigouvian level, causing motorists to switch to the replacement road. The result would be inefficiency and toll-gouging. This is another way that Knight's result is fragile.

We proceed as follows. In Section I, we discuss the planning problem and show why governmentimposed Pigouvian tolls induce self-interested motorists to act in ways that solve the planning problem. In Section II, we discuss the equilibrium with two or more congestible roads, each with an independent private toll-setter, and an untolled, uncongestible alternative of arbitrary speed. We compare the welfare of motorists and the aggregate toll revenue generated under private tolls and government-imposed tolls. In Section III, we conclude with a discussion of how private toll-setting can be regulated by potential competition from a public option. Convergence to the efficient allocation as the oligopolist toll-setting economy is replicated without bound is discussed in Appendix A, and technical details underlying one result are relegated to Appendix B.

\section{Overuse of Congestible Roads and Pigou's Proposal to Restore Efficiency}

Suppose that $N$ drivers must commute to work from the same starting point to the same destination using one of $n<\infty$ congestible roads and one uncongestible road. They have no alternatives to this commute. ${ }^{9}$ The cost incurred by drivers from choosing a given road is denoted in dollars of wages foregone while commuting. We assume that each motorist earns the same wage, and we denote the commuting cost (in dollars) on a congestible road $i$ as $A_{i}\left(x_{i}\right)$, where $x_{i}$ is the number of drivers on road $i{ }^{10}$ We assume that (i) $A_{i}\left(x_{i}\right)$ is differentiable, (ii) $A_{i}\left(x_{i}\right)$ is strictly increasing, and (iii) $x_{i} A_{i}\left(x_{i}\right)$ is strictly convex. To eliminate corner solutions, we also assume $A_{i}(0)=0$.

We denote the commuting cost on the fastest uncongestible road as $c$; if there are slower uncongestible roads (with even higher $c$ values), then we disregard them, because motorists would never use them. ${ }^{11}$ Therefore motorists choose between congestible roads, which increase in cost with the number of motorists on the road, and an uncongestible road, which provides a constant cost independent of the number of motorists on the road.

\section{The planning problem}

As a benchmark, consider how a planner would allocate $N$ motorists to the $n$ congestible roads and one uncongestible road to minimize the total cost of commuting in terms of forgone wages (or, equivalently, work hours lost while commuting):

$$
\sum_{i=1}^{n} x_{i} A_{i}\left(x_{i}\right)+\left(N-\sum_{i=1}^{n} x_{i}\right) c, \quad \text { subject to } N-\sum_{i=1}^{n} x_{i} \geq 0 .
$$

Since the minimand in the planning problem is strictly convex, the solution of the $n$ first-order conditions is unique.

The unique solution has one of two characteristics, depending on whether or not the planner finds using the uncongestible road to be optimal. In both, the planner equates the marginal social cost on each of the $n$ congestible roads:

$$
A_{i}\left(x_{i}^{s}\right)+x_{i}^{s} A_{i}^{\prime}\left(x_{i}^{s}\right)=A_{i+1}\left(x_{i+1}^{s}\right)+x_{i+1}^{s} A_{i+1}^{\prime}\left(x_{i+1}^{s}\right) \quad \text { for } i=1, \ldots, n-1,
$$

where the $n$ variables $\left\{x_{i}^{s}\right\}_{i=1}^{n}$ are defined as the socially efficient allocation of drivers. These $n-1$ equations are supplemented by a final equation. In the first case, the planner assigns some motorists to the uncongestible road:

$$
A_{i}\left(x_{i}^{s}\right)+x_{i}^{s} A_{i}^{\prime}\left(x_{i}^{s}\right)=c \quad\left(\text { and } N-\sum_{i=1}^{n} x_{i}^{s}>0\right) .
$$


In the second case, the planner does not use the uncongestible road:

$$
N-\sum_{i=1}^{n} x_{i}^{s}=0 \quad\left(\text { and } c-A_{i}\left(x_{i}^{s}\right)-x_{i}^{s} A_{i}^{\prime}\left(x_{i}^{s}\right)>0\right) .
$$

The planner utilizes the uncongestible road if and only if its exogenous commuting cost $c$ is smaller than the threshold cost, denoted $c_{K}$. Intuitively, if lost wages from using the uncongestible road are low $\left(c<c_{K}\right)$, then the planner will add motorists to every congestible road until its marginal social cost equals $c$, and will assign the remaining commuters to the uncongestible road. The higher $c$ is, the more commuters will be assigned to each congestible road and the fewer will be left for the uncongestible road. Eventually $c=c_{K}$ and all motorists will be on the congestible roads: $N-\sum_{i=1}^{n} x_{i}^{s}=0$. The threshold $c_{K}$ and the allocation $\left\{x_{i}^{s}\right\}_{i=1}^{n}$ are defined by the $n+1$ equations

$$
c_{K}=A_{i}\left(x_{i}^{s}\right)+x_{i}^{s} A_{i}^{\prime}\left(x_{i}^{s}\right) \text { for } i=1, \ldots, n, \quad \text { and } \quad N-\sum_{i=1}^{n} x_{i}^{s}=0 .
$$

For any $c>c_{K}$, the planner maintains this same allocation across the $n$ congestible roads and does not use the uncongestible road.

Pigou's proposal

Pigou (1920) points out that each motorist would adhere to the planner's solution if the government taxed each motorist for the use of congestible road $i$ at the rate of $\theta_{i}^{P}=x_{i}^{s} A_{i}^{\prime}\left(x_{i}^{s}\right)$ per trip. For in that case, when the motorist compared highways $i$ and $j$, he would discover that $A_{i}\left(x_{i}^{s}\right)+\theta_{i}^{P}=$ $A_{j}\left(x_{j}^{s}\right)+\theta_{j}^{P}$. Hence there would be no incentive to switch to a different route. If $c<c_{K}$, then $A_{i}\left(x_{i}^{s}\right)+\theta_{i}^{P}=c$ and the remainder of the motorists would use the untaxed and uncongestible road. If $c>c_{K}$, then all $N$ motorists would use the $n$ taxed roads: $N-\sum_{i=1}^{n} x_{i}^{s}=0$. In either case, Pigouvian tolls would implement the efficient solution for any number of roads. Pigou's solution is, therefore, completely general.

\section{Knight's Proposal to Privatize Toll-setting}

\section{Knight's response}

In response, Knight (1924) argues that government intervention is unnecessary. Private toll-setters in search of profits will always set their tolls at the levels recommended by Pigou; hence the private market will achieve the efficient allocation of motorists without any need for government intervention. Knight implicitly confines attention to the region where $c<c_{K}$ and hence $A_{i}\left(x_{i}\right)+$ $\theta_{i}=c$. Although Knight considers only the case of one congestible road, his conclusions are valid for $n \geq 2$ as well. ${ }^{12}$

Each of Knight's $n$ toll-setters maximizes revenue $x_{i} \theta_{i}$ subject to $A_{i}\left(x_{i}\right)+\theta_{i}=c$. That is, each toll-setter sets his toll simultaneously and anticipates that motorists will observe these $n$ tolls, conjecture the congestion on each road, and choose the route with the lowest overall cost (lost wages plus tolls). As a result, in each subgame indexed by the vector of tolls, the overall cost on every congestible road will equal $c$, the lost wages on the uncongestible road. Substituting out of $\theta_{i}$, each toll-setter maximizes $x_{i}\left(c-A_{i}\left(x_{i}\right)\right)$. Thus the allocation of the planner and the Nash equilibrium allocation coincide. Each solves $c-A_{i}\left(x_{i}\right)-x_{i} A^{\prime}\left(x_{i}\right)=0$. Denoting the number of motorists on road $i$ in the efficient solution as $x_{i}^{s}$ and in the Nash equilibrium as $x_{i}^{*}$, we conclude that $x_{i}^{*}=x_{i}^{s}$. Moreover, if we now use the constraint to solve for $\theta_{i}^{*}$ in the Nash equilibrium, then $\theta_{i}^{*}=x_{i}^{*} A_{i}^{\prime}\left(x_{i}^{*}\right)$. But since $x_{i}^{*}=x_{i}^{s}$, the private tolls would exactly match the user fees that Pigou recommended. That is, $\theta_{i}^{*}=\theta_{i}^{P}$.

Result $1\left(c<c_{K}\right)$. In the subgame-perfect equilibrium of the toll-setting game, private toll-setters will (i) charge tolls equal to the Pigouvian user fees, and therefore, in their quest for profits, (ii) achieve the efficient allocation.

Given the two conclusions in Result 1, assigning property rights and letting the private sector correct the congestion externality without any government intervention look appealing.

The failure of Knight's response

Although Knight's two conclusions are remarkable, they are misleading. As we will show, neither one survives when $c>c_{K}$. Commute times are then almost never minimized. And in the exceptional cases where they are minimized, every motorist always pays more in tolls than he would 
pay in Pigouvian user fees, even though his commute time is the same. Note that the efficient allocation is the same for all $c \geq c_{K}$, and is equal to the allocation at $c=c_{K}$, where no motorists uses the uncongestible option. In contrast, as we will see, the allocation with private toll-setters changes for different values of $c>c_{K}$.

To show this, we consider the case of $n \geq 2$ congestible roads in the absence of an uncongestible road. ${ }^{13}$ The toll chosen by player $i$ maximizes his revenue $\left(x_{i} \theta_{i}\right)$ and solves

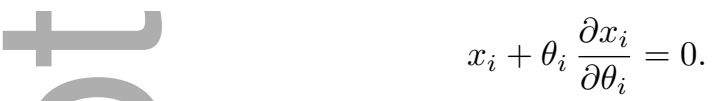

This condition says that when toll $i$ is set to maximize the revenue of player $i$, the amount of revenue lost from his old customers from lowering the toll by $\$ 1$ will equal the increase in revenue from attracting motorists from the road with an unchanged toll.

In a Nash equilibrium, four sets of conditions making up $2 n$ equations in the $2 n$ unknowns $\left\{\theta_{i}^{*}\right\}_{i=1}^{n},\left\{x_{i}^{*}\right\}_{i=1}^{n}$ must hold for $i=1, \ldots, n-1$ :

$$
\begin{aligned}
& A_{i}\left(x_{i}^{*}\right)+\theta_{i}^{*}=A_{i+1}^{*}\left(x_{i+1}^{*}\right)+\theta_{i+1}^{*} \quad(n-1 \text { conditions }), \\
& \sum_{i=1}^{n} x_{i}^{*}=N \quad(1 \text { condition }), \\
& \theta_{i}^{*}=x_{i}^{*}\left(A_{i}^{\prime}\left(x_{i}^{*}\right)+\left(1-\eta_{i}\right) A_{i+1}^{\prime}\left(x_{i+1}^{*}\right)\right) \quad(n-1 \text { conditions }), \\
& \theta_{n}^{*}=x_{n}^{*}\left(A_{n}^{\prime}\left(x_{n}^{*}\right)+\left(1-\eta_{n}\right) A_{1}^{\prime}\left(x_{1}^{*}\right)\right) \quad(1 \text { condition }),
\end{aligned}
$$

where

$$
\eta_{i}=-\frac{1}{\mathrm{~d} x_{i}} \sum_{k \neq i, i+1}^{n} \mathrm{~d} x_{k} \in[0,1) \text { for } i=1, \ldots, n-1 \quad \text { and } \quad \eta_{n}=-\frac{1}{\mathrm{~d} x_{n}} \sum_{k \neq n, 1}^{n} \mathrm{~d} x_{k} \in[0,1) .
$$

The first set of $n-1$ conditions holds since the overall cost, lost wages plus toll, must be equal across all roads - a consequence of the motorists' second-stage decisions. The second condition reflects the requirement that each motorist must use exactly one road. The third and fourth sets of conditions, respectively, are the first-order conditions for the toll-setters,

$$
x_{i}+\theta \frac{\partial x_{i}}{\partial \theta_{i}}=0 .
$$

To write the conditions in (2) and (3), we use the fact that

$$
\frac{\partial x_{i}}{\partial \theta_{i}}=-\left(A_{i}^{\prime}\left(x_{i}\right)+\left(1-\eta_{i}\right) A_{i+1}^{\prime}\left(x_{i+1}\right)\right)^{-1} .
$$

To derive this partial derivative, assume that only toll-setter $i$ changes his toll, and totally differentiate the equation indicating that the full cost per customer (lost wages plus the toll) is identical on roads $i$ and $i+1$ for any $i=1, \ldots, n-1$, and the equation indicating that all motorists must use one of the $n$ congestible roads. ${ }^{14}$ Since $\eta_{i}$ is the fraction of the motorists that leave road $i$ and go to all roads other than $\operatorname{road} i+1$, it is always smaller than 1 and equals 0 if and only if $n=2$. These equations must hold in a toll-setting equilibrium if there is no uncongestible road or if the uncongestible road is so slow that the full (equalized) cost of using the tolled, congestible roads is strictly cheaper. We denote the lowest cost with this property $c_{I}$, where $c_{I}=A_{i}\left(x_{i}^{*}\right)+\theta_{i}^{*}$. Under the privatization solution proposed by Knight, if $c>c_{I}$, then there are two possibilities.

Result $2\left(c>c_{I}\right)$. Under privatization, either (i) aggregate commute times are not minimized (the equilibrium is inefficient) or (ii) the equilibrium is efficient but workers pay higher tolls than they would under government-imposed Pigouvian tolls. ${ }^{15}$

Proof. To see that when private toll-setting minimizes aggregate commute times, every motorist pays higher than Pigouvian tolls, note that if $x_{i}^{*}=x_{i}^{s}$ for all $i$, then equations (3) and (4) imply that

$$
\theta_{i}^{*}=\theta_{i}^{P}+\left(1-\eta_{i}\right) x_{i}^{*} A_{i+1}^{\prime}\left(x_{i+1}\right)>\theta_{i}^{P} \quad \text { for } i=1, \ldots, n-1 .
$$

In addition,

$$
\theta_{n}^{*}=\theta_{n}^{P}+\left(1-\eta_{n}\right) x_{n}^{*} A_{1}^{\prime}\left(x_{1}\right)>\theta_{n}^{P}
$$


Private toll-setting is efficient in rare circumstances. It would always occur, for example, if each of the $n$ congestion functions were identical. For then the toll-setting equilibrium is symmetric and $N / n$ of the motorists use each road, as they would in the planning solution.

The following example demonstrates in the two symmetric roads case that the private tollsetting equilibrium is efficient but has higher tolls.

Example 1: Two symmetric roads.

Consider the case when $n=2$ and $A_{i}\left(x_{i}\right)=a_{i} x_{i}$, such that $a_{1}=a_{2}=a$. Aggregate commute time is minimized by dividing motorists so that $x_{1}=x_{2}=N / 2$. The Pigouvian tolls are given by $\theta_{i}^{P}=x_{i}^{s} A_{i}^{\prime}\left(x_{i}^{s}\right)=a x_{i}^{s}=a N / 2$. The equilibrium tolls are found by solving the system of equations in conditions $(1)-(4)$, which reduces to

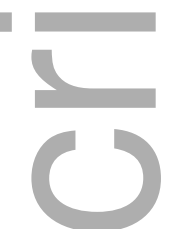

$$
\begin{aligned}
& a x_{1}+\theta_{1}^{*}=a x_{2}+\theta_{2}^{*}, \\
& x_{1}^{*}+x_{2}^{*}=N, \\
& \theta_{1}^{*}=x_{1}^{*}(a+a)=2 a x_{1}^{*}, \\
& \theta_{2}^{*}=x_{2}^{*}(a+a)=2 a x_{2}^{*} .
\end{aligned}
$$

In the privatized solution, the equilibrium tolls derived from this system of equations are $\theta_{1}^{*}=$ $\theta_{2}^{*}=2(a N / 2)=2 \theta_{1}^{P}=2 \theta_{2}^{P}$.

In this simple example, the socially efficient and privatized equilibrium number of motorists on each road is $N / 2$; but the tolls are twice as high in the privatized equilibrium.

However, unnecessarily long aggregate commute times (inefficiency) are more likely. The following example demonstrates that the private toll-setting equilibrium is inefficient with two asymmetric roads.

Example 2: Two asymmetric roads.

Consider the case when $n=2$ and $A_{i}\left(x_{i}\right)=a_{i} x_{i}$, such that $a_{1} \neq a_{2}$. Aggregate commute time is minimized by dividing motorists so that

$$
x_{1}^{s}=\frac{a_{2} N}{a_{1}+a_{2}} \quad \text { and } \quad x_{2}^{s}=\frac{a_{1} N}{a_{1}+a_{2}} .
$$

For motorists to allocate themselves in this way on the two roads, the duopolist toll-setters would have to set the same toll on each road. But any pair of private tolls that are equal would give at least one of these toll-setters a strict incentive to unilaterally deviate because conditions (3) and (4) would be violated: $x_{1}^{s}\left(a_{1}+a_{2}\right) \neq x_{2}^{s}\left(a_{2}+a_{1}\right) \cdot{ }^{16}$

What happens in the toll-setting equilibrium when the exogenous commute time on the uncongestible road is so long that a planner would not use it, $c>c_{K}$, but the cost of using this toll-free road in terms of lost wages is lower than the equilibrium cost to motorists of using any of the toll roads in the absence of an uncongestible alternative $c<c_{I}$ ? In this case, $c \in\left(c_{K}, c_{I}\right)$, the toll plus foregone wages on each road must equal the exogenous cost $c$, but every motorist nonetheless avoids the uncongestible road. ${ }^{17}$ In this intermediate case, the uncongestible road displaces the private toll-setting equilibrium by providing potential competition if toll-setters would raise their toll.

In a Nash equilibrium, the following $n+1$ equations in the $2 n$ unknowns $\left\{\theta_{i}^{*}\right\}_{i=1}^{n},\left\{x_{i}^{*}\right\}_{i=1}^{n}$ must hold:

$$
\begin{aligned}
& A_{i}\left(x_{i}^{*}\right)+\theta_{i}^{*}=A_{i+1}^{*}\left(x_{i+1}^{*}\right)+\theta_{i+1}^{*}, \quad i=1, \ldots, n-1 \quad(n-1 \text { conditions }), \\
& A_{1}\left(x_{1}^{*}\right)+\theta_{1}^{*}=c \quad(1 \text { condition }), \\
& \sum_{i=1}^{n} x_{i}^{*}=N \quad(1 \text { condition }) .
\end{aligned}
$$

The final set of conditions produces $n-1$ weak inequalities that ensure that no toll-setter can strictly benefit from raising or lowering his toll unilaterally, captured by

$$
\left.\frac{\partial R_{i}}{\partial \theta_{i}}\right|_{\theta_{-i}}=x_{i}+\left.\theta_{i} \frac{\partial x_{i}}{\partial \theta_{i}}\right|_{\theta_{-i}} .
$$

These conditions are inequalities because of the asymmetry in the response of motorists to a lowering or raising of a toll in this intermediate range, $c \in\left(c_{K}, c_{I}\right)$. In response to a unilateral

\section{This article is protected by copyright. All rights reserved}


lowering of a toll, motorists from other congestible roads move to the road with the now lower toll; no motorists are attracted from the uncongestible road since there are no motorists on it to attract:

$$
{\frac{\partial x_{i}}{\partial \theta_{i}}}^{-}=-\left(A_{i}^{\prime}\left(x_{i}\right)+\left(1-\eta_{i}\right) A_{i+1}^{\prime}\left(x_{i+1}\right)\right)^{-1} .
$$

In response to a unilateral raising of a toll, motorists leave that congestible road for the uncongestible road; no motorist moves to the other toll roads since, if anyone joined it, that road would become more congested and strictly less attractive than the uncongestible road:

$$
\frac{\partial x_{i}{ }^{+}}{\partial \theta_{i}}=-\left(A_{i}^{\prime}\left(x_{i}\right)\right)^{-1} \text {. }
$$

Intuitively, the magnitude of this response is smaller when the toll is reduced unilaterally because the other congestible roads (unlike the uncongestible road) become more attractive as motorists leave them. Because in an equilibrium, toll-setter $i$ cannot benefit from increasing or reducing his toll unilaterally, we have

$$
\frac{\partial R_{i}}{\partial \theta_{i}} \in\left(x_{i}^{*}-\frac{\theta_{i}}{A_{i}^{\prime}\left(x_{i}^{*}\right)}, x_{i}^{*}-\frac{\theta_{i}}{A_{i}^{\prime}\left(x_{i}^{*}\right)+\left(1-\eta_{i}\right) A_{i+1}^{\prime}\left(x_{i+1}^{*}\right)}\right) .
$$

We conclude that in a Nash equilibrium, the following weak inequalities must also hold for $i=$ $1, \ldots, n-1$ :

$$
x_{i}^{*}\left(A_{i}^{\prime}\left(x_{i}^{*}\right)+\left(1-\eta_{i}\right) A_{i+1}^{\prime}\left(x_{i+1}^{*}\right)\right) \geq \theta_{i}^{*} \geq x_{i}^{*} A_{i}^{\prime}\left(x_{i}^{*}\right)
$$

and

$$
x_{n}^{*}\left(A_{n}^{\prime}\left(x_{n}^{*}\right)+\left(1-\eta_{n}\right) A_{1}^{\prime}\left(x_{1}^{*}\right)\right) \geq \theta_{n}^{*} \geq x_{n}^{*} A_{n}^{\prime}\left(x_{n}^{*}\right) .
$$

These inequalities allow for a continuum of equilibrium tolls that satisfy the conditions (9)-(12). To characterize these equilibria, first note that when $c=c_{K}$, private toll-setters would duplicate Pigouvian user fees and the equilibrium allocation minimizes aggregate commute time. To verify this, note that when $x_{i}^{*}=x_{i}^{s}$ and $\theta_{i}^{*}=x_{i}^{s} A_{i}^{\prime}\left(x_{i}^{s}\right)=\theta_{i}^{P}$, conditions (9)-(12) are all satisfied. Note in particular that $\theta_{i}^{*}$ is at the lower end of each closed interval in (12).

If $c$ is $\Delta>0$ higher than $c_{K}$, then the same allocation of motorists across the congestible roads is efficient. This allocation can occur in a Nash equilibrium provided that each toll is also increased by $\Delta$. In that case, no motorist has an incentive to switch roads, so conditions (9)-(11) continue to hold. Moreover, as long as $\Delta<\min \left\{\left(1-\eta_{n}\right) x_{i}^{s} A_{i+1}^{\prime}\left(x_{i+1}^{s}\right)\right\}_{i=1}^{n-1}$, each $\theta_{i}^{*}$ will be in the interior of its respective closed interval. Although aggregate commute time is minimized in this equilibrium, each motorist would pay $\Delta>0$ more to private toll-setters than he would have paid in Pigouvian user fees.

For this same cost of the uncongestible road $\left(c_{K}+\Delta\right)$, there is a continuum of other equilibria. Since motorists are reallocated in these equilibria, each of them is inefficient. For example, if $\theta_{i}$ is raised slightly, then motorists will leave that toll road until its full cost falls back to $c_{K}+\Delta$. These additional motorists will raise congestion on the $n-1$ other toll roads, and in the new equilibrium $\theta_{j}$ for $j \neq i$ must be decreased slightly so that the full cost there is restored to $c_{K}+\Delta$.

Panel A of Figure 1 (constructed from an example with linear congestion functions and $n=2$ ) compares the aggregate commute time in the efficient solution to the commute time in the tollsetting equilibrium for every exogenous speed on the uncongestible road. The aggregate commute time in the planning solution is strictly increasing in $c$ until $c=c_{K}$ and is constant thereafter since the planner finds the uncongestible road too slow to utilize.

\section{Figure 1 near here}

Aggregate commute time in the toll-setting equilibrium coincides with that in the planning solution for $c \leq c_{K}$. At the other extreme $\left(c \geq c_{I}\right)$, aggregate commute time is strictly longer than in the planning solution provided that the congestible roads are heterogeneous. In the intermediate region $\left(c \in\left(c_{K}, c_{I}\right)\right)$, there is a continuum of equilibria. In panel $\mathrm{A}$ of Figure $1, c_{F}$ divides this interval into two parts. For each $c \in\left(c_{K}, c_{F}\right)$ there is a continuum of equilibria, all but one of which is inefficient. For $c>c_{F}$, the Nash equilibrium never minimizes aggregate hours spent commuting (assuming that the congestible roads differ); this should not be surprising given the strict inefficiency of the Nash equilibrium at $c=c_{I} \cdot{ }^{18}$

Result $3\left(c \in\left(c_{K}, c_{I}\right)\right)$. 
(i) There is a continuum of equilibria. In each, no motorist uses the uncongestible road, but every motorist would find the uncongestible road strictly more attractive if the toll he is paying were unilaterally raised in the slightest.

(ii) For some values of $c$ in this interval, no equilibrium minimizes aggregate time lost commuting; for other values, every equilibrium but one in the continuum of equilibria is inefficient.

(iii) Whenever the equilibrium is efficient, and therefore every motorist has exactly the commute time as under Pigou's solution, every motorist pays a higher toll than if under Pigou's solution

To summarize, Knight's contention - that government intervention is unnecessary in congestion problems because private toll-setters will set access fees at the same levels as the government user fees recommended by Pigou - is mistaken. As Figure 1 makes clear, Knight's novel contention is correct for $c \leq c_{K} \cdot{ }^{19}$ Whenever $c>c_{K}$, Knight's claims are false. Private toll-setters will almost never minimize aggregate hours lost commuting; when they do, motorists will pay strictly more than in the solution proposed by Pigou. Thus private toll-setters never all set Pigouvian tolls except in the special case examined by Knight. In contrast, regardless of the speed of the uncongestible road, the government can always achieve efficiency by imposing the road-specific taxes proposed by Pigou.

\section{The welfare of motorists}

Motorists care about the full cost of commuting, that is, the sum of tolls paid plus wages foregone while en route to work. The welfare of each motorist increases when the full cost of commuting falls.

Knight shows - for the special case where $c \leq c_{K}$ - that the full cost to motorists is the same whether tolls are set by private toll-setters or by a government following Pigou's recommendations. Does Knight's insight generalize? The following result is definitive.

Result $4\left(c>c_{K}\right)$. In every equilibrium, every motorist is strictly worse off if toll-setting is left to the private sector than if tolls are set by the government at Pigouvian levels.

To see why this is true, note that under Pigouvian tolls the full cost on every motorist's use equalizes, and the resulting allocation of motorists to roads is efficient. With the uncongestible road speed $c<c_{K}$, this means that the full cost on all $n+1$ roads is $c$. With the uncongestible road speed $c>c_{K}$, the uncongestible road is empty and the full cost on the $n$ congestible roads is $c_{k}$.

On the other hand, private toll-setters limit-price when $c \in\left(c_{K}, c_{I}\right]$, so for $c$ in this intermediate interval, the full cost to each motorist under private toll-setting increases linearly from $c_{K}$ to $c_{I} .{ }^{20}$

If $c$ is even larger $\left(c>c_{I}\right)$, then the full cost paid by each motorist under Pigou's solution remains constant at $c_{K}$, while the full cost under Knight's private-market solution remains constant at $c_{I}>c_{K}$. The full cost paid by each motorist under Pigou's proposal and under Knight's proposal is depicted in panel B of Figure 1.

We conclude this subsection by noting an apparent paradox. Suppose that a new congestible road is built and the toll on it is set by an additional profit-maximizer. If the uncongestible road continues to offer actual or potential competition for the $n+1$ congestible roads, then, paradoxically, motorists are no better off than before construction of the new road, regardless of their route to work. Even though commuters earn more because they get to work sooner, all of their additional earnings are paid in tolls. The full cost to them remains $c$.

We note that this paradox differs from the two celebrated paradoxes in the literature: the Pigou-Knight-Downs paradox (Downs 1962; Arnott and Small 1994) and Braess's paradox (Braess 1968; Murchland 1970). ${ }^{21}$ Both of these concern paradoxical behaviour in an equilibrium without toll-setters when an additional road is made available to motorists. Our paradox occurs in an equilibrium with toll-setting.

Toll revenue: does private toll-setting generate more revenue?

When an additional road is built and the private builder sets its access toll to maximize profit, the toll not only alters congestion on competing routes (and hence aggregate time commuting) but also generates revenue that can be used to finance, in part or in whole, the road construction. We therefore conclude by asking whether toll-setting by the private sector generates more revenue than government toll-setting. Obviously not, since the government can duplicate the private-sector 
tolls. However, it may not be clear that the private-sector tolls are almost surely inferior. We close this subsection with our final result.

Result $5\left(c>c_{K}\right)$. Whenever private toll-setting in inefficient, the government can set tolls in a way that simultaneously generates (1) strictly more aggregate toll revenue, (2) strictly less aggregate time lost commuting, and (3) strictly lower full cost for every motorist.

With private toll-setting, the full cost to motorists of using alternate routes will equalize (at $\min \left(c, c_{I}\right)$ ), but when $c>c_{K}$ the allocation is likely to be inefficient. With government-imposed Pigouvian tolls, the full cost to motorists will equalize at a lower level $\left(c_{K}\right)$, and if one adds the same fee $\left(\min \left(c, c_{I}\right)-c_{K}\right)$ to each Pigouvian toll so that the full cost of each route is the same $\left(\min \left(c, c_{I}\right)\right)$ as under private toll-setting, then aggregate commute time will remain strictly lower (since it is minimized) - hence aggregate toll revenue will be strictly higher than if the private sector sets tolls. Since these two inequalities are strict, they will continue to hold even if each addition to the Pigouvian tolls is reduced by some small $\varepsilon>0$. But with the toll on road $i$ of $\theta_{i}^{P}+\min \left(c, c_{I}\right)-c_{K}-\varepsilon$, the full cost to each motorist will also be smaller than when the tolls are set by the private sector.

Thus Knight's private-sector toll-setting is never better for motorists, and whenever $c>c_{K}$, it is strictly worse for them than government-implemented tolls. However, politicians currently favour private toll-setting. As Bertrand Russell (1936) remarked in another context, the case for government-imposed tolls 'ignores those higher considerations that transcend mere logic'. If the private market must be relied on, then our analysis suggests how the government can limit the full costs inflicted on commuters. We discuss government provision of an uncongestible 'public option' in the concluding section.

\section{Conclusion}

This paper has revisited the debate between Pigou and Knight about how to correct the inefficient use of congestible resources. Pigou favours access fees set by the government, while Knight favours access fees set by private toll-setters. Although congestion problems abound (as any internet user, commercial airline passenger or commercial fisherman can attest), we framed our discussion in terms of congestible roads - the example Knight and Pigou used in their original debate.

Pigou argues that the government should impose road-specific Pigouvian tolls on motorists using congestible roads to induce them to take full account of the negative social cost that their use imposes on fellow commuters in terms of aggregate wages foregone. Knight responds that government intervention is never necessary since private toll-setters in pursuit of maximum profit would set tolls at exactly the level Pigou recommended and hence would achieve efficiency without government meddling. The debate centred on the case where commuters could choose between a single congestible road and the fastest uncongestible alternative, and was further limited to the special case where that alternative was fast enough to be utilized in the commute-time minimizing solution.

We have examined the issues debated by Knight and Pigou more generally, considering the case of two or more congestible roads and one uncongestible road of any exogenous speed. We have shown that Pigou's proposed governmental solution is correct regardless of the commute time on the uncongestible road and regardless of the number of congestible alternatives. In contrast, Knight's private solution is, in general, incorrect. Private toll-setters can never be relied on to set Pigouvian tolls except in the special case to which Knight confined attention. Beyond that case, Knight's proposed solution almost never minimizes aggregate commute time. If the uncongestible alternative is sufficiently slow $\left(c \geq c_{F}\right)$, then none of the profiles of tolls that arise in equilibrium minimizes aggregate commute time; if the uncongestible alternative is somewhat faster $\left(c \in\left(c_{K}, c_{F}\right)\right)$, then only one among a continuum of equilibrium toll profiles minimizes aggregate commute time.

We also considered the impact of private toll-setting on the welfare of motorists. While commute time is important to them because of the foregone wages, so are the tolls that they must pay to get to work. We concluded that motorists are never better off, and for $c>c_{K}$ are strictly worse off if the private sector sets tolls, than under Pigou's proposal.

If private toll-setters are nonetheless allowed the freedom to set tolls on congestible roadways, then our analysis suggests how the government can complement private toll-setters to limit the costs that workers must bear. Specifically, the government can provide an uncongestible (or nearly so) alternative as a public option. ${ }^{22}$ In the context of roads, the government could provide a train, varying the number of cars, speed, and time between departures to ensure that this option was sufficiently uncongestible. If the train is sufficiently fast that some motorists ride it, then it will

\section{This article is protected by copyright. All rights reserved}


complement tolls set by the private sector by ensuring that those tolls allocate motorists across roads efficiently. But even if the train is slow, such that only non-motorists (such as seniors and other discounted fare riders) use it, then the train could still complement private-sector tolls if it induced limit-pricing by toll-setters. ${ }^{23}$ In this case, the full cost to motorists of commuting on private toll roads would be limited by the full cost at the margin of taking the train.

\section{APPENDIX A: EFFICIENCY RESTORED IN THE TOLL-SETTING GAME IN THE LIMIT OF A REPLICA ECONOMY}

Suppose that instead of $N$ motorists spread across $n$ motorways congestible to different extents, there is an $M$-fold replication with $M N$ motorists spread across $n$ types of congestible roads, with $M$ identical roads of each type. We wish to show that as $M \rightarrow \infty$, the efficient allocation of motorists can be supported as a subgame-perfect equilibrium of the toll-setting game. ${ }^{24}$

The efficient solution in this case uniquely solves the following $n+1$ equations defining $\left\{x_{i}^{s}\right\}_{i=1}^{n}$ and $\lambda^{s}$ :

$$
A_{i}\left(x_{i}^{s}\right)+x_{i}^{s} A_{i}^{\prime}\left(x_{i}^{s}\right)=\lambda^{s}, i=1, \ldots, n, \quad \text { and } \quad \sum_{i=1}^{n} x_{i}^{s}=N
$$

where $\lambda^{s}$ denotes the value of the Lagrangian multiplier at the social optimum.

Define the Pigouvian tolls as $\theta_{i}^{P}=x_{i}^{s} A_{i}^{\prime}\left(x_{i}^{s}\right)$ for $i=1, \ldots, n$. Suppose at the first stage of the two-stage game, every player but one type $i$ chooses the Pigouvian toll, while this one remaining type $i$ player chooses some $\theta_{i} \in\left[\theta_{i}^{\min }, \theta_{i}^{\max }\right]$. Define these minimum and maximum tolls as $\theta_{1}^{\max }=\mu-A_{1}(0)$ and $\theta_{1}^{\min }=\mu-A_{1}(M N)$, where $\mu$ in the first condition is equal to $\min \left\{A_{j}(0)+\theta_{j}^{P}\right\}$ and in the second is equal to the common cost given by $A_{j}\left(x_{j}\right)+\theta_{j}^{P}$. Then in the Nash equilibrium of the second stage, the motorists will allocate themselves so that the full cost (the toll plus the lost wages) is the same on every motorway. Denote this common cost as $\mu$. Then the following $n+2$ equations define the $n+2$ variables $x_{i}^{d},\left\{x_{j}\right\}_{j=1}^{n}$ and $\mu$ :

$$
\begin{aligned}
& A_{i}\left(x_{i}^{d}\right)+\theta_{i}=\mu, \\
& A_{j}\left(x_{j}\right)+x_{j}^{s} A_{j}^{\prime}\left(x_{j}^{s}\right)=\mu \quad \text { for } j=1, \ldots, n, \\
& x_{i}^{d}+(M-1) x_{i}+M \sum_{j \neq i} x_{j}=N .
\end{aligned}
$$

Anticipating these second-stage responses and conjecturing that the other toll-setters will maintain their tolls at the Pigouvian level, the deviating type $i$ player can set any toll $\theta_{i}$ in the closed interval. A marginal increase in his toll would then cause his profits to increase at the rate

$$
\frac{\partial \pi_{i}}{\partial \theta_{i}}=\frac{\partial\left(\theta_{i} x_{i}^{d}\left(\theta_{i}\right)\right)}{\partial \theta_{i}}=x_{i}^{d}+\theta_{i} \frac{\partial x_{i}}{\partial \theta_{i}} .
$$

Let $\theta_{i}=\varepsilon_{i}+\theta_{i}^{P}=\varepsilon_{i}+x_{i}^{s} A_{i}^{\prime}\left(x_{i}^{s}\right)$. Differentiating equation (A1), we obtain

$$
\frac{\partial x_{i}}{\partial \theta_{i}}=\left(\frac{\partial \mu}{\partial \theta_{i}}-1\right) \frac{1}{A_{i}^{\prime}\left(x_{i}^{d}\right)}
$$

Substituting for $\theta_{i}$ and recognizing that as $M \rightarrow \infty, \partial \mu / \partial \theta_{i} \rightarrow 0$, we conclude that

$$
\frac{\partial \pi_{i}}{\partial \theta_{i}}=\frac{x_{i}^{d} A_{i}^{\prime}\left(x_{i}^{d}\right)-x_{i}^{s} A_{i}^{\prime}\left(x_{i}^{s}\right)-\varepsilon_{i}}{A_{i}^{\prime}\left(x_{i}^{d}\right)} .
$$

If $\varepsilon=0$, then the toll under consideration is the Pigouvian toll. By definition, $x_{i}^{d}=x_{i}^{s}$. So the expression in (A4) equals zero. If $\varepsilon>0$, then the toll exceeds the Pigouvian level $\left(\theta_{i}>\theta_{i}^{P}\right)$, less than the efficient number of motorists take the route $\left(x_{i}^{d}<x_{i}^{s}\right)$, and the expression in (A4) is strictly negative. Finally, if $\varepsilon<0$, then the toll is smaller than the Pigouvian level $\left(\theta_{i}<\theta_{i}^{P}\right)$, more than the efficient number of motorists take the route $\left(x_{i}^{d}>x_{i}^{s}\right)$, and the expression in $(\mathrm{A} 4)$ is strictly positive.

It follows that for any toll $\theta_{i}$ in the closed interval, the payoff of player $i$ is single-peaked at the Pigouvian toll. Moreover, any toll so high that no one uses the motorway, or so low that raising it would not alter the number of motorists using his route, is clearly suboptimal for toll-setter $i$. But these arguments apply to every toll-setter. Hence, in the limit, no toll-setter has a strict incentive 
to deviate unilaterally from the profile of Pigouvian tolls, even when there is no uncongestible motorway.

Intuitively, for any $M$, the efficient number of motorists on any road of a given type does not change. Moreover, for any profile of tolls, the number of motorists choosing a roadway of a given type does not change. What changes is the rate at which a toll-setter on a road of a given type anticipates that he will lose customers if he marginally increases his toll. For small $M$, this rate of loss is dampened since every competing road is rendered less attractive as the motorists fleeing the increased toll add to its congestion. But as $M$ grows, the fleeing motorists locate on so many different roads that the additional congestion imposed on any one of them becomes negligible. In the limit, therefore, it is as if the alternative to any individual toll-setter's road is a completely uncongestible alternative.

Assigning property rights to toll-setters eliminates the inefficiency in a thick market because the effect of a change in toll on one road has increasingly less effect on the number of drivers on other roads until in the limit $\mathrm{d} x_{j} / \mathrm{d} \theta_{i} \rightarrow 0$. In this case the second term that produces the wedge in $-\mathrm{d} \theta_{1} / \mathrm{d} x_{1}=A_{1}^{\prime}\left(x_{1}\right)+A_{2}^{\prime}\left(x_{2}\right)$ goes to zero and efficiency is restored.

Knight (1924, p. 591) alludes vaguely to 'competitive conditions' being necessary for his result, but never clarifies what such conditions entail. They entail either (1) an uncongestible road fast enough that a planner would utilize it, or, in the absence of such a road, (2) a replica economy with a sufficiently large number of roads of each type.

\section{APPENDIX B: DERIVING THE CONDITIONS FOR NASH EQUILIBRIUM IN THE TOLL-SETTING GAME}

The first-order condition for the revenue-maximizing toll-setter is

$$
x_{i}+\theta_{i} \frac{\partial x_{i}}{\partial \theta_{i}}=0
$$

which can be rewritten as

$$
\theta_{i}=-x_{i}\left(\frac{\partial x_{i}}{\partial \theta_{i}}\right)^{-1}
$$

To derive $\partial x_{i} / \partial \theta_{i}$, we totally differentiate the conditions that indicate that all motorists must be on one of the congestible roads, and the full cost of driving on road $i$ is equal to the full cost of driving on road $j$ :

$$
\sum_{i=1}^{n} x_{i}=N, \quad \mathrm{~d} x_{i+1}=-\mathrm{d} x_{i}-\sum_{k \neq i, i+1}^{n} \mathrm{~d} x_{k} .
$$

Notice that if $\mathrm{d} x_{i}<0$, as is the case in $\mathrm{d} x_{i} / \mathrm{d} \theta_{i}$, then $\sum_{k \neq i, i+1}^{n} \mathrm{~d} x_{k} \geq 0 .{ }^{25}$ Intuitively, this says that if the number of motorists on road $i$ decreases, due to the toll being raised on road $i$, then the number of motorists on all of the other roads will weakly increase:

$$
\begin{aligned}
& A_{i}\left(x_{i}\right)+\theta_{i}=A_{i+1}\left(x_{i+1}\right)+\theta_{i+1}, \\
& A_{i}^{\prime}\left(x_{i}\right) \mathrm{d} x_{i}+\mathrm{d} \theta_{i}=A_{i+1}^{\prime}\left(x_{i+1}\right) \mathrm{d} x_{i+1}, \\
& A_{i}^{\prime}\left(x_{i}\right) \mathrm{d} x_{i}+\mathrm{d} \theta_{i}=-A_{i+1}^{\prime}\left(x_{i+1}\right) \mathrm{d} x_{i}-A_{i+1}^{\prime}\left(x_{i+1}\right) \sum_{k \neq i, i+1}^{n} \mathrm{~d} x_{k}, \\
& A_{i}^{\prime}\left(x_{i}\right) \mathrm{d} x_{i}+\mathrm{d} \theta_{i}=-A_{i+1}^{\prime}\left(x_{i+1}\right) \mathrm{d} x_{i}+A_{i+1}^{\prime}\left(x_{i+1}\right) \eta_{i} \mathrm{~d} x_{i}, \\
& \left(A_{i}^{\prime}\left(x_{i}\right)+\left(1-\eta_{i}\right) A_{i+1}^{\prime}\left(x_{i+1}\right)\right) \mathrm{d} x_{i}=-\mathrm{d} \theta_{i}, \\
& \frac{\mathrm{d} x_{i}}{\mathrm{~d} \theta_{i}}=-\left(A_{i}^{\prime}\left(x_{i}\right)+\left(1-\eta_{i}\right) A_{i+1}^{\prime}\left(x_{i+1}\right)\right)^{-1},
\end{aligned}
$$

where

$$
\eta_{i}=-\frac{1}{\mathrm{~d} x_{i}} \sum_{k \neq i, i+1}^{n} \mathrm{~d} x_{k} \in[0,1) .
$$

The derivation of equation (4) is virtually identical. 
We would like to thank Rabah Amir, Natalia Lazzati, Molly Macauley and Jidong Zhou for comments on a previous draft, as well as seminar participants at the University of Iowa's Department of Economics, the Montreal Natural Resources and Environmental Economics Workshop, and conference participants in the 19th Annual Conference of the International Society for New Institutional Economics (ISNIE).

\section{NOTES}

1. President Trump's plan is summarized in Zanona (2017). The liberal response is summarized by Krugman (2016). He writes: 'Imagine that you are building a toll road. If the government builds it, it ends up paying interest but gets the future revenue from the tolls. If it turns the project over to private investors, it avoids the interest cost-but also loses the future toll revenue. The government's future cash flow is no better than it would have been if it borrowed directly ....'

2. Cheung (1973, footnote 2), for example, interprets Pigou's withdrawal of the highway example from his opus as an attempt to avoid further criticism by Knight.

3. For this reason, one should anticipate fierce opposition to a public option from the private toll-setter lobby.

4. Prizes are becoming an important mechanism in many areas. See Brennan et al. (2011) for a partial list. We thank the late Molly Macauley for helpful discussions on this application.

5. The debate also stimulated a related literature on 'club goods', originating with Buchanan (1965). Many others followed this intellectually attractive approach, including Ellickson et al. (1999). The competitive equilibria of clubs are also discussed by Berglas (1976, 1981), Berglas and Pines (1981), Boadway (1980), Berglas et al. (1982), Hillman and Swan (1983), Sandler and Tschirhart (1980), Scotchmer (1994), and Scotchmer and Wooders (1987). Seegert (2011) discusses the equilibrium in clubs in the context of cities.

6. Vickrey (1963) is one of his earliest contributions, and a survey of Vickrey's influential work is given in Arnott et al. (1994).

7. For more on second-best pricing and auction mechanisms, see Verhoef (2002a,b, 2007), Verhoef and Small (2004), and Ubbels and Verhoef (2008).

8. Edelson (1971) finds that Knight's private solution is inefficient when it is extended to the case of two congestible roads, but Edelson's demonstration is marred by his assumption that only one of those congestible roads has a toll-setter. To see the problem, suppose that the two roads are identical. Then a planner would assign half of the motorists to each road, but in Edelson's formulation, the lone toll-setter would set a strictly positive toll and would attract less than half of the motorists. This is clearly inefficient, but the source of the inefficiency is the absence of the second toll-setter. Once a second toll-setter is introduced, the equilibrium becomes symmetric, with equal tolls on the two roads and half the motorists on each road. Hence Edelson's formulation was the source of the inefficiency in this example. Therefore it cannot be ruled out as the source more generally.

9. In more general formulations, motorists have different alternatives to this commute so $N$ is endogenous.

10. Throughout, we treat the number of drivers on $\operatorname{road} i\left(\operatorname{denoted} x_{i}\right)$ as a real number rather than an integer.

11. Our model follows Knight and Pigou in the context of roads, but in a model sufficiently general to be applicable to other settings with congestion. For models with more detailed application to road congestion, see Braid (1989, 1996), Verhoef et al. (1996, 1997), and Verheof (2007).

12. For $n=1$, private tolls induce efficiency even when $c \geq c_{K}$, because in that case, it is efficient that all $N$ motorists use the congestible road.

13. Many readers will regard the case where no alternative is uncongestible as the rule rather than the exception.

\section{This article is protected by copyright. All rights reserved}


14. See Appendix B for details.

15. As shown in Appendix A, efficiency does reappear as a limiting result in a replica economy.

16. To see that inefficiency is not an artefact of linearity, replace each linear congestion function with a strictly convex congestion function tangent to it at $x_{i}^{s}$. Since $N, A_{i}\left(x_{i}^{s}\right), A_{i}^{\prime}\left(x_{i}^{s}\right)$ and $x_{i}^{s}$ are unchanged from the linear case, the same division of the motorists will still solve the equations for an efficient allocation but will still violate conditions (3) and (4).

17. Readers preferring a derivation of the best-reply of each duopolist in response to any conjectured toll of the other player (even non-equilibrium conjectures) should consult Salant and Seegert (2014).

18. As depicted in Figure 1, there are even equilibria with aggregate commute times longer than in the solution with no uncongestible road. We provide intuition here and refer readers to Salant and Seegert (2014) for a proof. Suppose that there are two congestible roads with different congestion functions, and consider the aggregate commute time in the unique but inefficient equilibrium when $c=c_{I}$. Suppose that $c$ is reduced by some small $\Delta>0$. If both tolls are reduced by that amount, then the aggregate commute time will not change. Suppose that aggregate commute time could be reduced if fewer motorists traveled on road 1. If instead more motorists travelled on road 1, then aggregate commute times would be even longer than in the unique equilibrium when $c=c_{I}$. This assignment of motorists can be supported as a Nash equilibrium by setting the tolls on the two roads so that the full cost on each road is $c_{I}-\Delta$. Then no motorist wants to deviate unilaterally since the full cost of the three alternative routes is the same; and a unilateral deviation by either toll-setter would strictly reduce his toll revenue.

19. This is at first surprising since the well-known conditions for a market solution to be efficient are violated; but the conditions of the first welfare theorem are sufficient, not necessary, conditions for efficiency. As discussed in Appendix A, Knight's claims are also true if the numbers of road types and motorists are replicated without bound. But this is hardly a realistic situation.

20. It is striking that the full cost to motorists is the same $(c)$ across the continuum of equilibria induced by any given $c \in\left(c_{K}, c_{I}\right)$ although the aggregate cost in lost wages increases monotonically as one moves vertically up in panel A of Figure 1. Motorists pay a full cost of $c N$, of which $c N-\sum_{i=1}^{n} x_{i} A_{i}\left(x_{i}\right)$ is paid in tolls. Since the aggregate cost in lost wages is smallest at each point on the lower boundary in panel A of Figure 1, aggregate toll revenue must be largest in that equilibrium. Toll revenue decreases monotonically as one moves due north.

21. In the Pigou-Knight-Downs paradox, the addition of a fast but congestible road with the same origin and destination as the others will not reduce anyone's commute time if the uncongestible road continues to be used after the new road is made available; the new road merely absorbs some of the traffic that used to use the uncongestible alternative. In Braess's paradox, the additional road connects the two congestible roads and may be uncongestible and lightning fast. Congestion worsens in the scramble to access the new road.

22. Following Knight and Pigou, we have assumed that the alternative without a toll-setter is uncongestible. But if that option were instead slightly congestible, our points would continue to hold. If the train were sufficiently slow (even without passengers to congest it), then its provision would not displace the toll-setting equilibrium. If the train were sufficiently fast (when uncongested), then its provision would attract some motorists, providing actual competition; if the train was of intermediate speed, then its provision would provide 'potential competition' since the slightest unilateral increase in any toll would induce the first motorists to switch to the train. Of course, in this intermediate case, the train need not run empty since non-motorists could take advantage of it.

23. For it to be effective, the full cost of commuting by train would have to be smaller than the full cost of commuting by the next best uncongestible alternative.

24. Seegert (2011) demonstrates the efficiency of this system in the limiting case in the context of a system of cities.

\section{This article is protected by copyright. All rights reserved}


25. If toll-setter $i$ increases his toll unilaterally, then he must conjecture that the marginal costs of the $n-1$ roads with unchanged tolls rise or fall in unison to remain equal to each other. However, they cannot fall since then congestion on road $i$ would also have to fall for its marginal cost to match the others despite $i$ 's toll increase, and this would leave some of the $N$ motorists with no road to drive on. So toll-setter $i$ will conjecture that if he raises his toll, then congestion on each road with an unchanged toll will strictly increase, which implies the assertion in the text.

\section{REFERENCES}

Arnott, R. and Small, K. (1994). The economics of traffic congestion. American Scientist, 82(5), 446-55.

Arrow, K., Atkinson, A. B. and Dreze, J. H. (1994). Public Economics: Selected Papers by William Vickrey. Cambridge: Cambridge University Press.

ASCE (2017). 2017 infrastructure report card by the American Society of Civil Engineers; available online at www.infrastructurereportcard.org/wp-content/uploads/2017/01/Roads-Final.pdf (accessed 15 October 2017).

Beckmann, M., McGuire, C. B. and Winsten, C. B. (1956). Studies in the Economics of Transportation. New Haven, CT: Yale University Press.

Berglas, E. (1976). On the theory of clubs. American Economic Review, 66, 116-21.

- (1981). The market provision of club goods once again. Journal of Public Economics, 15(3), 389-93.

— and Pines, D. (1981). Clubs, local public goods and transportation models: a synthesis. Journal of Public Economics, 15(2), 141-62.

- Helpman, E. and Pines, D. (1982). The economic theory of clubs: some clarifications. Economics Letters, 10(3), 343-8.

Boadway, R. (1980). A note on the market provision of club goods. Journal of Public Economics, 13(1), $131-7$.

Borenstein, S., Bushnell, J. and Stoft, S. (2000). The competitive effects of transmission capacity in a deregulated electricity industry. RAND Journal of Economics, 31(2), 294-325.

BraEss, D. (1968). Über ein paradoxon aus der verkehrsplanung. Unternehmensforschung, 12(1), 258-68.

BRAID, R. M. (1989). Uniform versus peak-load pricing of a bottleneck with elastic demand. Journal of Urban Economics, 26(3), 320-7.

- (1996). Peak-load pricing of a transportation route with an unpriced substitute. Journal of Urban Economics, 40(2), 179-97.

Brennan, T., Macauley, M. and Whitefoot, K. (2011). Prizes, patents, and technology procurement: a proposed analytical framework. Resources for the Future Discussion Paper no. $11-21$.

Brueckner, J. K. (2002). Airport congestion when carriers have market power. American Economic Review, 92, 1357-75.

Buchanan, J. M. (1956). Private ownership and common usage: the road case re-examined. Southern Economic Journal, 22, 305-16.

- (1965). An economic theory of clubs. Economica, 32, 1-14.

Cheung, S. N. S. (1973). The fable of the bees: an economic investigation. Journal of Law and Economics, 16, 11-33.

Demsetz, H. (2011). The problem of social cost: what problem? A critique of the reasoning of AC Pigou and RH Coase. Review of Law and Economics, 7(1), 1-13.

Downs, A. (1962). The law of peak-hour expressway congestion. Traffic Quarterly, 16(3), 393-409.

Edelson, N. M. (1971). Congestion tolls under monopoly. American Economic Review, 61, 873-82.

Ellickson, B., Grodal, B., Scotchmer, S. and Zame, W. R. (1999). Clubs and the market. Econometrica, 67(5), 1185-217.

Ellis, H. S. and Fellner, W. (1943). External economies and diseconomies. American Economic Review, 33(3), 493-511.

Foxx, A. (2017). America's transportation problems. US News and World Report, 17 January.

Hillman, A. L. and Swan, P. L. (1983). Participation rules for Pareto-optimal clubs. Journal of Public Economics, 20(1), 55-76. 
Knight, F. H. (1924). Some fallacies in the interpretation of social cost. Quarterly Journal of Economics, 38(4), 582-606.

Krugman, P. (2016). Infrastructure build or privatization scam. New York Times, 19 November.

Mills, D. E., (1981). Ownership arrangements and congestion-prone facilities. American Economic Review, 71, 493-502.

Murchland, J. D. (1970). Braess's paradox of traffic flow. Transportation Research, 4(4), $391-4$.

Pels, E., NiJkamp, P. and Rietveld, P. (2000). Airport and airline competition for passengers departing from a large metropolitan area. Journal of Urban Economics, 48(1), 29-45.

Pigou, A. C. (1920). The Economics of Welfare. London: Macmillan.

Russell, B. (1936). The last survivor of a dead epoch. The Listener, 12 August, p. 289.

Salant, W. S. and Seegert, N. (2014). Private access fees and congestion: is there a role for government after all? RFF Discussion Paper no. 14-26-REV.

SANDlen, T. and Tschirhart, J. T. (1980). The economic theory of clubs: an evaluative survey. Journal of Economic Literature, 18, 1481-521.

SChumer, C. (2017). PBS Newshour, 23 January.

Scotchmer, S. (1994). Public goods and the invisible hand. In J. M. Quigley and E. Smolensky (eds), Modern Public Finance. Cambridge, MA: Harvard University Press, pp. 93-125.

— and Holtz Wooders, M. (1987). Competitive equilibrium and the core in club economies with anonymous crowding. Journal of Public Economics, 34(2), 159-73.

SEEgERT, N. (2011). Land regulations and the optimal distribution of cities; available online at http://ssrn.com/abstract=2557399 (accessed 16 October 2017).

UbBels, B. and Verhoef, E. T. (2008). Auctioning concessions for private roads. Transportation Research Part A: Policy and Practice, 42(1), 155-72.

VERHOEF, E. T. (2002a). Second-best congestion pricing in general networks: heuristic algorithms for finding second-best optimal toll levels and toll points. Transportation Research Part B: Methodological, 36(8), 707-29.

- (2002b). Second-best congestion pricing in general static transportation networks with elastic demands. Regional Science and Urban Economics, 32(3), 281-310.

(2007). Second-best road pricing through highway franchising. Journal of Urban Economics, 62(2), 337-61.

and SMall, K. A. (2004). Product differentiation on roads. Journal of Transport Economics and Policy, 38(1), 127-56.

—- Nijkamp, P. and Rietveld, P. (1996). Second-best congestion pricing: the case of an untolled alternative. Journal of Urban Economics, 40(3), 279-302.

$-1-$ and $=$ (1997). The social feasibility of road pricing: a case study for the Randstad area. Journal of Transport Economics and Policy, 31, 255-76.

Vickrey, W. S. (1963). Pricing in urban and suburban transport. American Economic Review, 53, $452-65$.

Zanona, M. (2017). Toll roads poised to boom under Trump plan. The Hill, 8 January.

\section{FIGURE CAPTION}

Figure 1. Commute time and full cost as speed on uncongestible road varies.

Notes: Panel A provides visual evidence that the commute times are never shorter and sometimes longer with private tolls (given by the solid curve and grey region). Panel B provides an example of the full cost (time and tolls) with Pigouvian tolls (dashed line) and private tolls (solid line). 